\title{
The Perceived Discrimination and Remittances: Evidence from Immigrants in Northern Italy
}

\author{
SARA SALOMONE \\ Ghent University, Belgium \\ UNU-CRIS (Institute on Comparative Regional Integration Studies), \\ Belgium
}

\author{
MAELAN LE GOFF \\ Bank of France, France
}

\begin{abstract}
Despite the fact that immigrants' experienced discrimination can imply higher economic and psychological migration costs, little research has explicitly focused on its role as remitting device. Using the 2012-2013 waves of an original survey docu- menting transnational economic immigrants in Northern Italy, this paper quanti es the relationship between perceived economic discrimination and amount remitted (intensive margin), conditional on remitting at all (extensive margin). Empirical results show that, beside traditional individual characteristics, a more discriminating destination environment leads to lower amount of remittances but only for women. The e ect mainly goes through female immigrants' labor market conditions and only slightly through the willingness to leave Lombardy.
\end{abstract}

\section{Keywords}

international migration, remittances, gender, discrimination

\section{Introduction}

In most OECD countries, discrimination against immigrants and their offspring remains a key issue. It is important both on the labour market, through unequal access to employment and subsequent career advancement and wages, and on the housing market and the education system (OECD, 2013). On average, women tend to be more affected by discriminatory practices than men in both European and non-European OECD countries. ${ }^{1}$ Notably, this concerns immigrants aged 15-24 in Europe, Canada and New Zealand, while in the United States older immigrants (aged 55-64) seem to feel worse off. As far as origins are concerned, immigrants born in lower income countries are the most discriminated, in particular, those coming from

\footnotetext{
1 Whether female migrants are more discriminated than males is still an open issue. The United Nations Population Fund has recently recognised the presence of a 'double disadvantage' experienced by female migrants as a consequence of being both migrants and women (UNFPA, 2006). According to Rubin et al. (2008), of the two dimensions of disadvantage (gender and migrant), the migrant unemployment differential (for women) is generally larger than the gender unemployment differential (for migrants). Moreover, comparing EU-born migrant women with those born in third countries reveals a third axis of disadvantage: third-country migrant women's unemployment rates are 5.6 percentage points higher than those of EU migrants ( $14 \%$ and $84 \%$ respectively).
} 
sub-Saharan African and Latin American regions. If we look at their educational level, outcomes are contradictory, with the low educated (ISCED 0-2) feeling discriminated in Europe and United States and the high educated (ISCED 5/6) experiencing discrimination in Canada and New Zealand. ${ }^{2}$

Through its negative impact on social cohesion and immigrants' incentives to invest in education and training, discrimination experienced by immigrants can represent an economic loss to both host and sending countries. Focusing on the latter perspective, this paper looks at the effects of immigrants' perceived discrimination in the host country on remitting behaviour, by empirically quantifying both the extensive (probability to remit) and intensive (the amount remitted) margins. Individual level data comes from the ORIM survey data provided by the Foundation for Initiatives and Studies on Multi- Ethnicity (ISMU) which monitors the immigration experience to the Lombardy region, which is located in the North of Italy.

From being one of the major European emigration countries until the mid1970 's, Italy has gradually evolved, as have Greece, Spain, or Portugal to some extent, into a net immigration country. Italy has become one of the most popular European destinations for migrants, with a stock of 5.7 million foreign born people in 2012, representing 9.6\% of the total population (OECD, 2014). Between 2008 and 2012, the total stock of foreign born people increased by an average of $7 \%$ a year. Most of the immigrants have settled in the north or in the centre of Italy, which are the most prosperous and therefore the most attractive regions. Lombardy, which is the most preferred immigration destination in the northern central part of Italy, is bordered by Switzerland (to the north) and four other Italian regions: Trentino-Alto Adige, Veneto (east), Emilia-Romagna (south), and Piedmont (west). According to the 2011 Census, Lombardy hosted $23.5 \%$ of Italy's foreign residents $(8.2 \%$ in the province of Milan) at the national level, followed by Veneto (11\%), Emilia Romagna (11\%) and Lazio (10.6\%).

Looking at a more disaggregated territorial level, Lombardy holds the second highest incidence of foreigners in the total resident population, with a share of $11.3 \%$, with the highest incidence belonging to the Emilia Romagna with 12\% (Bettin and Cela, 2014).

The role of immigrants' perceived discrimination on remitting behavior is a priori ambiguous. Perceived discrimination can imply higher economic and psychological costs as has been described by Dancygier et al. (2014), who

2 The following sources have been used: European OECD countries: European Social Survey, 2002- 2010. Canadian General Social Survey, cycle 23, 2009; New Zealand General Social Survey 2008; United States 2004-2012 General Social Surveys. 
review the economic discrimination experienced by immigrants in Europe, and the work of Lowell et al. (1995) on Hispanics' labour conditions in the United States. More particularly, for psychological effects of ethnic discrimination, Yip et al. (2008) consider the experience of Asians in the United States. While for the effects on the quality of life, Ng et al. (2015) document the experience of Chinese immigrants in Hong Kong. These costs can in turn affect labour outcomes, which are responsible for remitting behavior (Docquier and Rapoport, 2006). However, the magnitude and direction of the relationship between the two variables are not straightforward $(w \downarrow \uparrow)$. On one hand, there can be an income effect $(\downarrow)$ due to an unequal access to the labour market and/or the so called 'brain waste' which is defined as the difference in the occupational attainment of immigrants having similar education backgrounds but belonging to different nationalities. ${ }^{3}$ In other words, migrants would remit less because of a lower disposable income to be spent both locally and transnationally. On the other hand, there can be a return intention effect $(\uparrow)$. Remittances can increase if discrimination influences return migration for people residing abroad (Dustmann and Mestres, 2010). Indeed, the time spent in the destination country 4 decreases as a consequence of heavy workloads with long working hours, limited training facilities, poor career development as well as recorded abuses. If the risk of being prevented from staying in a destination country increases, this may affect the return decisions of immigrants currently living in the host country ${ }^{5}$. Immigrants expecting a relatively short stay in the host country will have higher savings and/or send more remittances to their home country. Thirdly, the two effects can be jointly present.

Little research has addressed this issue and in a partial way, in considering the first but not the second channel. Carling and Hoelscher (2013) describe the role of perceived discrimination - as a fundamental dimension of sociocultural integration together with language proficiency and a sense of belonging - on the capacity to remit for immigrants residing in Norway. While discrimination does not significantly affect remittance-behaviour, the authors find that economic integration, mainly defined as labour market position ${ }^{6}$, is crucial. Gorodzeisky and Semyonoy (2006) confirm previous conclusions, considering Filipino immigrants' labour market discrimination in a gendered perspective. They show how remitting behavior differs

\footnotetext{
3 See Ozden (2006), who focuses on the United States, concluding that highly educated immigrants from certain countries are less likely to obtain skilled jobs. Among the groups with the lowest likelihood of obtaining skilled jobs are migrants from several Latin American, Eastern European, and Middle Eastern countries.

4 See Dustmann and Gorlach (2015) for a comprehensive literature review on the temporariness of migration.

5 There is evidence that this holds at least for refugees having experienced lower levels of integration at destination. See di Sant Pierre et al., 2015.

6 Individuals are asked whether they have had difficulties with regular and unexpected expenses; whether they are employed; whether they receive pension and whether they have a certain degree of security.
} 
between male and female immigrants as a consequence of individual gendered characteristics and earning disparities. More importantly, the net effect of gender on earnings seems to have a cumulative effect on the differential ability of men and women to remit. According to them, about 70 percent of the gender gap in remittances may be viewed as a net effect of gender. Yet only 25 percent of this gap is attributed to earnings differentials between men and women. Apparently, net earnings disparities between men and women (after adjustment for living expenses) are considerably larger than the gross earnings gap. Cortes (2015) also considers a gendered environment in her work on Filipino female migrants. She finds that migrant mothers send significantly fewer remittances than Filipino fathers because they are underemployed. This is due to the fact that most female migrants are working in relatively low remunerated occupations, such as domestic workers. From a broader perspective, Lowell and Marcelli (2005), analyse the role of social capital on the amount of remittances sent back home from Mexican immigrants residing in Los Angeles. They conclude that remittances are positively related to immigrant home-ownership in Los Angeles County and negatively associated with having had public health insurance such as Medicaid. Finally, Siegel (2007) provided evidence on the positive relationship between the level of immigrants' integration at their destination and the formal channel chosen to send remittances.

Our work pays exclusive attention to perceived economic discrimination while also taking into account differences between men and women. We find that, besides traditional individual economic and non-economic characteristics, a more discriminating destination environment leads to lower amount of remittances, but only for women. More importantly, in exploring the possible channels at work as in Bollard et al. (2011), we find that the effect mainly goes through female immigrants' labour market conditions and only slightly through the willingness to leave Lombardy. The results are worthy of note since they suggest that ethnic discrimination in the global economy may have an indirect effect on the economic conditions of households left behind in the local economy through a considerable reduction in remittances.

The remainder of this paper is organised as follows. Section 2 describes the datasets used to conduct the empirical analysis. Section 3 provides the two specifications estimated distinguishing between a base specification and an augmented one with gender discrimination interactions. Finally, Section 4 concludes.

\section{The Data}

To analyse the relationship between remittances and discrimination, we use micro data from the Foundation for Initiatives and Studies on Multi-Ethnicity 
(ISMU) which monitors the immigration experience to the Lombardy region, the most preferred immigration destination in Italy. The survey of interest conducted by the Regional Observatory for Integration and Multi-ethnicity (ORIM) relies on the Centre Sampling (CS method hence-forth) method, which is a sampling technique developed and implemented by the ISMU Foundation, particularly in reference to the study of the immigrant population. Its main advantage consists of allowing us to track legal as well as illegal immigrants, which is the main shortcoming in using alternative sources such as administrative and survey data (Baio et al., 2011). ${ }^{7}$

Vogel and Kovacheva (2008) provide evidence on the high reliability of this method and its wide applicability to follow the so called 'hidden populations', such as immigrants without a regular permit. Indeed, the CS method enables us to carry out a probabilistic survey even in the situation where the list of statistical units representing the universe of reference is missing or partially incomplete, as in the case of surveys targeting all migrants without regard to their juridical status. It overcomes this obstacle by exploiting social interactions within the immigrant population. Indeed, the CS technique is based on the likelihood/need for both legal and illegal migrants to join local aggregation centres for social contacts, health care, religion, leisure or simply for everyday needs. The full list of aggregation centres (institutions, places of worship or entertainment, care centres, meeting points, shops, telephone centres, etc.) can be fairly easily mapped by an informed researcher. Once a sufficiently wide and heterogeneous set of centres is identified, it is possible to randomly identify a sample of centres, and then randomly choose a sample of immigrants among the attendees of each selected centre. Notice that the number of interviews in a certain centre will depend on its size, with smaller centres given a smaller probability to be chosen than larger ones. It is important to underline that the final sample of immigrants obtained following this procedure cannot be representative of the whole reference population. Indeed, the inclusion probability of a given immigrant in a given centre depends positively on the number of centres he/she visits, and negatively on the number of regular attendees of centres. However, the probability of inclusion can be obtained ex-post, and used to compute a set of weighting coefficients that correct for the inclusion probability of each immigrant in the sample. This weighted sample has the same representativeness as a simple random sample (SRS) drawn

\footnotetext{
7 It is worth noting that there are other estimation methods that can be implemented to provide information on the whole immigrant population, or to complement the existing data sources on regular migration with specific figures on stocks and flows of undocumented migrants. A detailed discussion of alternative methods can be found in the CLANDESTINO Project, which reviews the state of the art on the topic of illegal immigration in Europe, critically describes the features and the critiques of the existing methods, and assesses the quality of the available estimates obtained with different techniques (Jandl et al., 2008).
} 
proportionally from the distribution of attendance pro le in the universe of reference.

Finally, the stock of immigrants can be estimated reconciling the CS weighted data with the population registry data, augmenting the number of registered immigrants by the proportion of respondents declining to be listed in the population registry. Other than providing a valid estimate of the size of the immigrant population, the second advantage of the data collection carried out by ISMU Foundation using the CS method is that it is specifically customised in order to give a detailed picture of the migration phenomenon. Indeed, relative to official data sources, the survey contains more precise and detailed information on the demographic and socio-economic characteristics of the immigrant population from 2002 to 2013. Moreover, the survey collects valuable and unique information on specific aspects related to the migration phenomenon, such as on integration processes, paths in and out the illegal status, remitting behaviour, and perceived discrimination.

For the purpose of this study, the benchmark model deals with individual remitting behaviour and perceived discrimination plus other traditional individual characteristics discussed at length in Section 3.1. Specifically, since information on perceived discrimination is available only for years 2012 and 2013, while replies concerning remitting behaviour are available over a longer time interval (from 2004 to 2013), our final time span is limited to years 2012 and 2013. The sample of interest includes 3,457 immigrants (with 1345 women and 2112 men) whose individual characteristics are provided in Table 1. Immigrants come from 104 origins from all over the world 8 . As Table 2 shows, the most important origin country is Morocco, followed by Egypt and Ukraine. Where female immigrants are concerned, Ukrainian women are the most widespread both in absolute numbers and in relative terms (as a percentage of the total migrant population). The over-representation of females among migrants is observable also in the case of other Eastern European countries (Moldavia, 84\%; Romania, 71\%), but also in Peru (67\%) and in Ecuador (63\%). As far as male immigrants are concerned, Egyptians are the most numerous in absolute terms and males from Pakistan in relative numbers (Table 2). 
Table 1: Characteristics of Respondents

\begin{tabular}{lll}
\hline & Survey & Sample \\
\hline Female & 0.47 & 0.39 \\
Age & 38.9 & 37.9 \\
Years of stay & 10.7 & 8.6 \\
Education & 2.5 & 2.5 \\
Children & 0.93 & 0.14 \\
Children abroad & 0.45 & 0.85 \\
Legal status & 0.89 & 0.81 \\
Income & 688.9 & 687.5 \\
Regular work & 0.58 & 0.60 \\
\hline
\end{tabular}

Source: Authors' calculations based on ORIM Data (2012-2013)

\subsection{Remitting behaviour}

Remitting behaviour is defined in the Survey at household level as the 'mean monthly household amount expenses for remittances'. It belongs to an array of questions available from 2004 to 2013 related to household monthly income expenditures for food and clothes, housing (loan and rent) and savings. In particular, the question reads as follows:

'How much of your household income is monthly spent for remittances?' Since this work looks at individual remitting behaviour', we have restricted the sample of interest to those households where just one working-age migrant (a man or a woman) is present as main remitter. A working age migrant is an individual aged 25+ years old, who lives with neither his parents nor his children aged more than 18 years old. ${ }^{10}$ Concerning the remitting behaviour of the selected sample of interest, $64 \%$ of the immigrants remit. Among the remitters, the monthly amount of remittances is around 265 euros. The percentage of remitters is similar among females and males, with

\footnotetext{
9 In contrast to this basic model in which decisions are made by one individual, some evidence suggests that migration decisions are frequently taken at household level (Stark, 1991; Lessem, 2013).

10 Although this strategy makes us lose two thirds of the observations originally included in the survey, it allows us to focus on economic migrants who migrated alone or/and who are more likely to have left their family behind. According to Dustmann and Mestres (2010) support for remaining family members, as well as savings for future consumption, investments held in origin country and insurance against a future return are the primary motives for remitting.
} 
The Perceived Discrimination and Remittances, Salomone and Le Goff

Table 2: Top origin countries

\begin{tabular}{llllll}
\hline Origin country & total & females & males & \% females & $\%$ males \\
\hline Morocco & 405 & 101 & 304 & 0,24 & 0,75 \\
Egypt & 268 & 7 & 261 & 0,02 & 0,97 \\
Ukraine & 268 & 257 & 11 & 0,95 & 0,04 \\
Senegal & 256 & 16 & 240 & 0,06 & 0,93 \\
Romania & 194 & 139 & 55 & 0,71 & 0,28 \\
Pakistan & 150 & 3 & 147 & 0,02 & 0,98 \\
Tunisia & 117 & 14 & 103 & 0,11 & 0,88 \\
Peru & 116 & 78 & 38 & 0,67 & 0,32 \\
Albania & 106 & 38 & 68 & 0,35 & 0,64 \\
India & 102 & 12 & 90 & 0,11 & 0,88 \\
Moldova & 101 & 85 & 16 & 0,84 & 0,15 \\
Ivory Coast & 87 & 27 & 60 & 0,31 & 0,68 \\
Ecuador & 83 & 53 & 30 & 0,63 & 0,36 \\
China & 80 & 48 & 32 & 0,6 & 0,4 \\
\hline
\end{tabular}

Source: Authors' calculations based on ORIM Data (2012-2013)

$65 \%$ of women remitting monthly compared to $63 \%$ of men. However, the amount of remittances sent back home varies by gender with women remitting a mean amount of 304 euros per month while men remit only 236 euros. The average monthly amount of remittances differs also by country of origin, as shown in Figure 1. The best remitters are the Ukrainian migrants, who send back around 360 euros per month, followed by Indians and Romanians. The ones who remit least are migrants from the Ivory Coast with 192 euros per month. 


\section{Figure 1: Average Monthly Amount of Remittances by Origin Country}

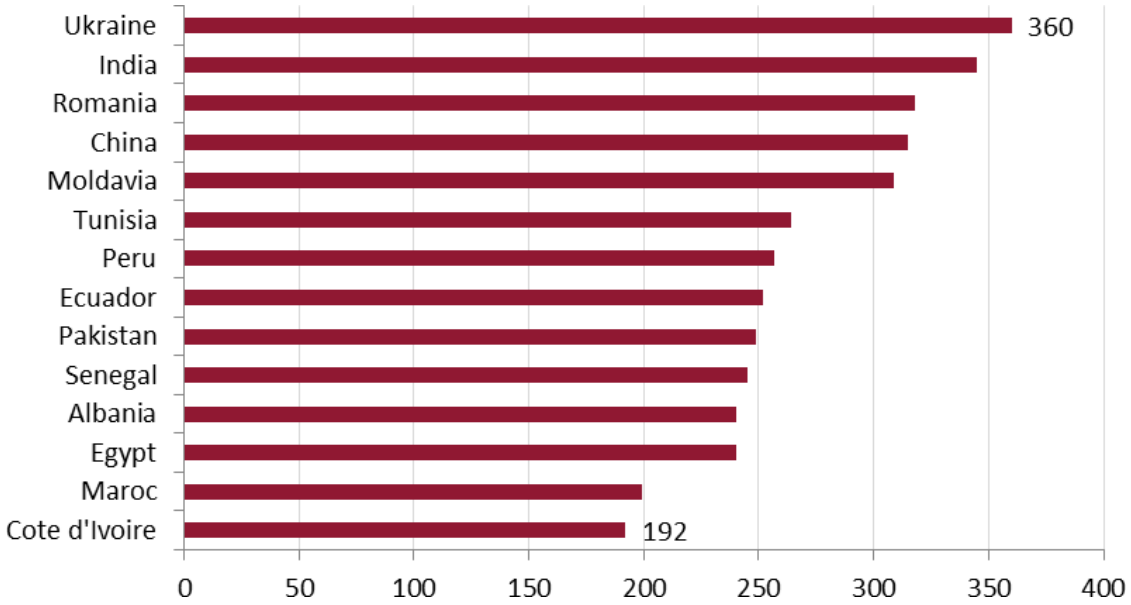

Source: Authors' calculations based on ORIM Data (2012-2013)

\subsection{Perceived discrimination}

The specific information provided in the survey on perceived discrimination relates to multiple dimensions. Immigrants are questioned about discrimination experienced in six different environments namely at work, at school, on the house search, with services, with the police and in relationship. In this paper we focus on the first one, whose question reads as follows: 'Have you experienced a discriminating situation at work during the last 12 months?'11

In our sample, while female migrants feel less concerned with discrimination at work than males (13\% versus 19\%), perceived discrimination tends to be more associated with discrimination experienced by females on the labour market (Table 3) if individual income and regular employment are concerned.

Figure 2 shows that, in addition to gender and being a migrant, discrimination can depend on the country of origin of the migrants. ${ }^{12}$ Migrants from sub-Saharan Africa, for example, are more likely to experience workplace discrimination than those coming from other areas.

11 Summary statistics on the other forms of perceived discrimination have been calculated by the authors and are available upon request.

12 There is evidence of the so called 'third axis of discrimination' raised by Rubin et al. (2008). 


\section{Table 3: Workplace Discrimination and Situation in the Labour Market in our Sample}

\begin{tabular}{llll}
\hline \multirow{2}{*}{ Females } & & $\begin{array}{l}\text { Individual income } \\
\text { (in euros) }\end{array}$ & $\begin{array}{l}\text { Regular work } \\
\text { (in \%) }\end{array}$ \\
\cline { 3 - 4 } Total & Workplace discrimination=1 & 880 & 54.5 \\
& Workplace discrimination=0 & 937 & 75.5 \\
& Workplace discrimination=1 & 990 & 52.8 \\
& Workplace discrimination=0 & 1005 & 47.5 \\
& Workplace discrimination=0 & 974 & 56.7 \\
& Sample average & 970 & 60.8 \\
\hline
\end{tabular}

Source: Authors' calculations based on ORIM Data (2012-2013)

In our sample, all Mozambican immigrants declared having faced discrimination at work during the last twelve months. Moreover, among the countries which are mostly concerned with discrimination (implying that more than $20 \%$ of the respondents experienced workplace discrimination), there are eleven countries belonging to sub-Saharan Africa.

Figure 2: Perceived Discrimination among Migrants (\%) by Country of Origin

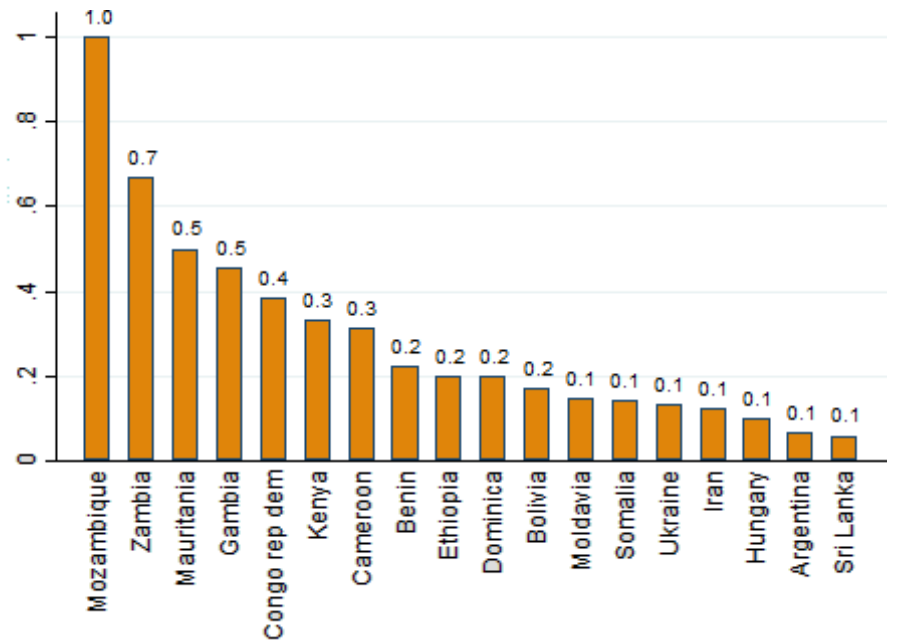

Source: Authors' calculations based on ORIM Data (2012-2013) 


\section{Empirics}

\subsection{Empirical strategy}

To examine the effect of perceived discrimination on migrants' remitting behaviour, we first estimate the extensive (the probability of remitting) and secondly, the intensive margin of remittances (the average monthly amount of remittances).

$$
\text { Remittances }_{i}=\beta_{1} \text { discrimination }+\beta_{2} X_{i}+\gamma_{i}+\delta_{p}+\varepsilon_{i}
$$

The dependent variable $\operatorname{Rem}_{i}$ is either a binary variable that takes the value 1 if the respondent $i$ sends monthly remittances and 0 otherwise, or the amount of monthly remittances sent by the respondent $i . X_{i}$ represents a vector of individual demographic and socio-economic characteristics expected to influence both the probability of remitting and the amount remitted. They include age, marital status, legal status, number of children abroad, total number of children, education, duration of stay in Italy, level of income and gender. The variable of interest discrimination $i$ is a dummy variable equal to 1 if the migrant $i$ has experienced discrimination at work during the last 12 months. To account for observed and unobserved heterogeneity at the destination (e.g. labour market characteristics) and specific remittance behaviour at origin level we also include country of birth (Daldy et al. 2013) $\gamma_{i}$ and destination provincial $\delta_{p}$ fixed effects. Destination provinces and origin-region fixed effects are also important to control for the selection of specific types of individuals into migration and their sorting into specific provinces (Licuanan et al., 2015).

We estimate different specifications of this econometric model. We start by estimating a model for the extensive margin of remittances (i.e. the migrant's decision of whether to remit or not). For this purpose, we run a Probit model where the dependent variable is a binary variable equal to 1 if the individual migrant sent any form of remittances in the year of the survey, and we include all controls described above. More specifically, the Probit specification is as follows:

$$
\operatorname{Pr}\left(Y_{i}=1 \mid X_{i}\right)=\Phi\left(\beta_{1} x_{i}+X_{i} \beta\right)+\gamma_{i}+\delta_{p}+\varepsilon_{i}
$$


where $Y_{i}$ is a binary variable taking value 1 when individual $i$ sent any remittances to the origin country; $\beta_{1}$ is the main coefficient of interest linked to economic discrimination. $X_{i}$ is the vector of control variables described previously, which are likely correlated with remittances behaviour. We are also interested in the amount of remittances sent, the intensive margin, and use a zero censored Tobit model to account for the significant proportion of individuals that have not sent any remittances in the year prior to the survey. There are a number of alternative solutions to the issue of zero censoring in remittance data. Bettin et al. (2012) suggest using the double hurdle and Heckit models to account for the possibility of different mechanisms influencing the decision to remit and the amount to be remitted (as in Batista and Umbljis, 2015). While this has the advantage of accounting for nonremittance due to budgetary constraints, this type of model can be sensitive to identification exclusions. This is especially a problem for data on remittances, as finding realistic variables that affect the decision to remit money, but not the amount, are difficult to conceive of (Amuedo-Dorantes and Pozo, 2006) ${ }^{13}$. Therefore, we opt for the Tobit model, which accounts for the zero censoring without the identification issues of the selection models. More specifically our econometric specification is:

$$
\begin{gathered}
Y_{i}^{*}=\beta_{1} x_{i 1}+X_{i}^{\prime} \beta+\gamma_{i}+\delta_{p}+\varepsilon_{i} \\
Y_{i}=\max \left(0, Y_{i}^{*}\right) \\
\varepsilon_{i} \sim N\left(0, \sigma^{2}\right)
\end{gathered}
$$

where the latent variable $Y_{i}^{*}$ is modelled as depending on the same independent variables as those included in the Probit model, and the dependent variable $Y_{i}$ is the $\log$ of the zero censored amount remitted in Euros in the current year. Because remittances are not normally distributed, the transformation in log is required.

13 Hence, while we are able to reduce the problem of unobserved heterogeneity across migrants' origin households that is present in this kind of studies, we do not claim to estimate a true causal effect of individual perceived discrimination on remitting behaviour. 


\subsection{Results}

Table 4 provides estimation results on the relationship between remittances and traditional variables of interest considering the whole sample of interest when economic discrimination is not taken into account. Marginal effects of Probit estimates and Tobit estimates are reported. For the Probit specification, the dependent variable is a dummy taking value 1 when the migrant sends remittances in the year prior to the survey. For the Tobit specification, it is the amount remitted in EUR in the year before the survey. First, our results show that the sign and the significance levels of each traditional control variable is preserved according to the literature. We observe that remittances follow a U-shaped pattern if age is taken into consideration, with the probability to remit and the amount of remittances raising in early age and falling in old age. As expected, the remitting behaviour is strongly influenced by linkages to the home country: having a spouse and/or children abroad positively affects the propensity to remit and the amount of remittances, while the duration of residence in the host country produces the opposite effect as already shown by Dustmann and Gorlach (2015). On the effect of education on remittances, we find a negative relationship which supports that strand of literature providing evidence that more educated migrants remit less. Indeed, more educated migrants often come from richer families and have a higher propensity to migrate with their entire household (hence, less need to send remittances) and a lower propensity to return, reducing the incentives to remit as a way of maintaining prestige and ties to the home community. However, gender surprisingly affects neither the decision to remit nor the value of monthly remittances at this stage.

Table 5 employs the same covariates of interest as in Table 4 by adding economic discrimination experienced by immigrants in Northern Italy. In particular, columns 1 and 2 consider the full sample of interest while from column 3 onward the gender dimension of the respondent is exploited, presuming that discrimination experienced at work can impact men and women's remitting behaviour in a different way. Regarding our variable of interest, we find that the effect of perceived economic discrimination significantly and negatively affects the value of monthly remittances sent by female migrants, while it does not influence males' remittances. This outcome is in line with the positive correlation found at macro level by Le Goff and Salomone (2015) on the recent feminisation of international migration and the increase in remittances' flows. Moreover, it implies that women remit less as a consequence of having been discriminated on the labour market. Of course, nothing can be inferred in terms of causal impact ${ }^{14}$ but it highlights an

\footnotetext{
${ }^{14}$ In this empirical setting, we cannot control for endogeneity concerns due to reverse causality issues, given that our main covariate of interest (i.e. economic discrimination) has not been instrumented. Indeed, as Falco and Gobel (2015) show, migrants' desire to send remittances back home fosters integration.
} 
important statistical correlation to be further explored in the future. In the present study, we further explore the negative link between economic discrimination and gendered characteristics of immigrants by restricting the empirical analysis to women only (from Table 5 onwards) by accounting for any possible transmission channels at stake together with non-linearities.

\subsubsection{Transmission channels}

As discussed in Section 1, economic discrimination can affect remitting behaviour through two main channels: individual income and/or employment status and return intention. Table 3, and Figure 3 show that those female immigrants who feel discriminated against in the workplace earn less and are more likely to be employed irregularly on one hand, and are more willing to move elsewhere (within or outside Italy) on the other hand.

\section{Figure 3: Female Migrants' Willingness to Move in the Next 12 Months (\% of Respondents)}

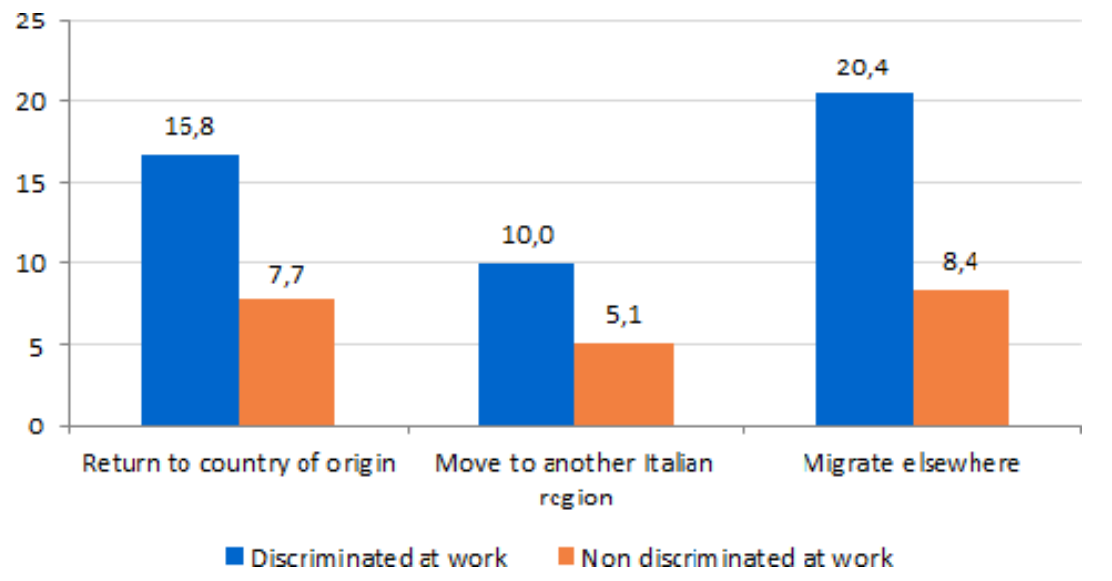

Source: Authors' calculations based on ORIM Data (2012-2013)

To disentangle the role of the above transmission channels, we consider specifically variables related to individual income and return intentions, and we add them one by one to observe how the coefficient associated to economic discrimination changes with respect to the baseline model (as in columns 1 and 2 of Table 6). From column 3 to 6 of Table 6, variables measuring immigrants' labour market conditions, as individual income and regular employment, are first included. Both of them are positive and significant in increasing the role of economic discrimination in discouraging the probability to remit and the amount remitted. From column 5 onward, leaving intentions are also taken into account. In particular, a first broader question on leaving Lombardy is added (columns 7 and 8), then a more specific question on the likelihood to come back to the home country 
(columns 9 and 10) and finally the intention to move to a third country (columns 11 and 12). The most important channels at work are the likelihood to come back home and the intention to move in another country different from Italy and the origin country. Coming back home affects positively the amount of remittances sent back home (Wolff, 2013) and strengthens the role of economic discrimination in decreasing both the probability and the amount remitted. Moving elsewhere, instead, decreases the amount of remittances sent back home given the additional costs the migrant is likely to incur where redefining her migration plan.

Overall, results presented in Table 6 suggest that the negative effect of workplace discrimination on remittances mainly passes through female immigrants' labour market conditions and the willingness to migrate elsewhere.

\section{Non linearities}

Table 7 also controls for non-linearities, showing that the discriminationremittances relationship varies with the level of income, education and the duration of stay in Italy. Our results in columns 1 and 2 show that the remittances-reducing effect of workplace discrimination decreases with migrants' level of income and education. On the contrary, column 3 indicates that while discrimination at workplace has a positive effect on remittances when migrants have just arrived, the effect becomes negative after a certain length of stay. This result may be explained by the decrease in the desire to leave with the migrants' duration of stay. As a brief, the remittances-reducing effect of workplace discrimination applies particularly to female migrants who are less educated, have a low income and are long-settled. 
Table 4: Probability of Remitting and Traditional Variables of Interest (Total Sample)

\begin{tabular}{|c|c|c|c|c|}
\hline & Probit & Tobit & Probit & Tobit \\
\hline \multirow[t]{2}{*}{ Age } & $0.070^{* * *}$ & $0.238^{* * *}$ & $0.071^{* * *}$ & $0.237^{* * *}$ \\
\hline & $(0.026)$ & $(0.087)$ & $(0.026)$ & $(0.087)$ \\
\hline \multirow[t]{2}{*}{ Age2 } & $-0.000^{* * *}$ & $-0.002^{* * *}$ & $-0.000^{* * *}$ & $-0.002^{* * *}$ \\
\hline & $(0.000281)$ & $(0.000)$ & $(0.000)$ & $(0.000)$ \\
\hline \multirow[t]{2}{*}{ Spouse abroad } & $0.320 * * *$ & $1.190^{* * *}$ & $0.315^{* * *}$ & $1.202^{* * *}$ \\
\hline & $(0.0977)$ & $(0.354)$ & $(0.0937)$ & $(0.345)$ \\
\hline \multirow[t]{2}{*}{ Legal } & $0.157^{* *}$ & $0.618^{* *}$ & $0.159 * *$ & $0.612^{* *}$ \\
\hline & $(0.0693)$ & $(0.275)$ & $(0.0702)$ & $(0.282)$ \\
\hline \multirow[t]{2}{*}{ Children abroad } & $0.509 * * *$ & $1.638^{* * *}$ & $0.504^{* * *}$ & $1.649^{* * *}$ \\
\hline & $(0.0566)$ & $(0.186)$ & $(0.0599)$ & (0.199) \\
\hline \multirow[t]{2}{*}{ Children } & $-0.316^{* * *}$ & $-1.049^{* * *}$ & $-0.312^{* * *}$ & $-1.059 * * *$ \\
\hline & $(0.0528)$ & $(0.219)$ & $(0.0556)$ & $(0.230)$ \\
\hline \multirow[t]{2}{*}{ Education } & $-0.054^{*}$ & -0.077 & $-0.053^{*}$ & -0.079 \\
\hline & $(0.0302)$ & $(0.099)$ & $(0.030)$ & $(0.099)$ \\
\hline \multirow[t]{2}{*}{ Duration of stay } & $-0.017^{* *}$ & $-0.050^{* *}$ & $-0.017^{* *}$ & $-0.049 * *$ \\
\hline & $(0.007)$ & $(0.021)$ & $(0.006)$ & $(0.021)$ \\
\hline \multirow[t]{2}{*}{ Female } & & & -0.0344 & 0.0971 \\
\hline & & & $(0.065)$ & $(0.278)$ \\
\hline Constant & $-1.046^{*}$ & $-5.769^{* * *}$ & $-1.060^{*}$ & $-5.735^{* * *}$ \\
\hline Observations & 3,38 & 2,89 & 3,38 & 2,89 \\
\hline
\end{tabular}


Table 5: Probability of Remitting and Workplace Discrimination Total sample Male sample Female sample

\begin{tabular}{|c|c|c|c|c|c|c|}
\hline & Probit & Tobit & Probit & Tobit & Probit & Tobit \\
\hline \multirow[t]{2}{*}{ Workplace discr. } & -0.0109 & -0.0407 & 0.0712 & 0.198 & -0.198 & $-0.388 * * *$ \\
\hline & $(0.057)$ & $(0.157)$ & $(0.067)$ & $(0.255)$ & $(0.130)$ & $(0.0141)$ \\
\hline \multirow[t]{2}{*}{ Age } & $0.0708 * * *$ & $0.238 * * *$ & $0.0920 * *$ & $0.376^{* *}$ & $0.0767 * *$ & $0.271 * * *$ \\
\hline & $(0.026)$ & $(0.087)$ & $(0.044)$ & $(0.171)$ & $(0.035)$ & $(0.000)$ \\
\hline \multirow[t]{2}{*}{ Age squared } & $-0.000 * * *$ & $-0.002 * * *$ & $-0.001 * *$ & $-0.004 * *$ & $-0.000 * *$ & $-0.002 * * *$ \\
\hline & $(0.000)$ & $(0.000)$ & $(0.000)$ & $(0.001)$ & $(0.000)$ & $(1.22 \mathrm{e}-05)$ \\
\hline \multirow[t]{2}{*}{ Spouse abroad } & $0.319 * * *$ & $1.189 * * *$ & $0.359 * * *$ & $1.555 * * *$ & 0.212 & $0.613 * * *$ \\
\hline & $(0.098)$ & $(0.355)$ & $(0.102)$ & $(0.338)$ & $(0.132)$ & $(0.036)$ \\
\hline \multirow[t]{2}{*}{ Legal } & $0.156^{* *}$ & $0.617^{* *}$ & $0.223 * *$ & $1.071 * * *$ & -0.0230 & $-0.225 * * *$ \\
\hline & $(0.0697)$ & $(0.279)$ & $(0.0871)$ & $(0.311)$ & $(0.139)$ & $(0.018)$ \\
\hline \multirow[t]{2}{*}{ Children abroad } & $0.509 * * *$ & $1.638 * * *$ & $0.366 * * *$ & $1.190 * * *$ & $0.645 * * *$ & $1.817 * * *$ \\
\hline & $(0.0564)$ & $(0.186)$ & $(0.107)$ & $(0.390)$ & $(0.0856)$ & $(0.023)$ \\
\hline \multirow[t]{2}{*}{ Children } & $-0.317 * * *$ & $-1.049 * * *$ & $-0.233 * *$ & $-0.730 * *$ & $-0.309 * * *$ & $-0.969 * * *$ \\
\hline & $(0.052)$ & $(0.218)$ & $(0.093)$ & $(0.368)$ & $(0.073)$ & $(0.022)$ \\
\hline \multirow[t]{2}{*}{ Education } & $-0.054^{*}$ & -0.077 & -0.051 & -0.029 & -0.0558 & $-0.130 * * *$ \\
\hline & $(0.030)$ & $(0.099)$ & $(0.042)$ & $(0.141)$ & $(0.045)$ & $(0.003)$ \\
\hline \multirow[t]{2}{*}{ Duration of stay } & $-0.017 * *$ & $-0.050 * *$ & -0.000 & -0.0038 & $-0.035 * * *$ & $-0.086^{* * *}$ \\
\hline & $(0.007)$ & $(0.021)$ & $(0.006)$ & $(0.022)$ & $(0.011)$ & $(0.001)$ \\
\hline Constant & $-1.046^{*}$ & $-5.770 * * *$ & -1.428 & $-8.904 * *$ & -0.336 & $-26.37 * * *$ \\
\hline Observations & 3,38 & 2,89 & 2,049 & 1,717 & 1,275 & 1,173 \\
\hline
\end{tabular}

* Significant at the $10 \%$ level ** $5 \%$ level *** $1 \%$ level. The standard errors in parentheses are clustered by country of origin. 
Table 6: Probability of Remitting and Workplace Discrimination (Females Only)

\begin{tabular}{|c|c|c|c|c|c|c|c|c|c|c|c|c|}
\hline \multicolumn{13}{|c|}{ Female sample } \\
\hline & Probit & Tobit & Probit & Tobit & Probit & Tobit & Probit & Tobit & Probit & Tobit & Probit & Tobit \\
\hline \multirow{2}{*}{$\begin{array}{l}\text { Workplace } \\
\text { discrimination }\end{array}$} & -0.198 & $-0.388 * * *$ & -0.200 & $-0.303^{* * *}$ & -0.194 & $-0.276^{* * *}$ & $-0.214^{*}$ & $-0.305^{* * *}$ & $-0.216^{*}$ & $-0.325^{* * *}$ & $-0.214^{*}$ & $-0.305^{* * *}$ \\
\hline & $(0.130)$ & $(0.0141)$ & $(0.132)$ & $(0.011)$ & $(0.123)$ & $(0.0121)$ & $(0.138)$ & $(0.0172)$ & $(0.128)$ & $(0.135)$ & $(0.138)$ & $(0.016)$ \\
\hline \multirow[t]{2}{*}{ Income (log) } & & & 0.013 & $0.680^{* * *}$ & -0.0149 & $0.606^{* * *}$ & -0.013 & $0.601^{* * *}$ & -0.012 & $0.603^{* * *}$ & -0.013 & $0.603^{* * *}$ \\
\hline & & & $(0.020)$ & $(0.001)$ & $(0.021)$ & $(0.001)$ & $(0.022)$ & $(0.001)$ & $(0.021)$ & $(0.001)$ & $(0.022)$ & $(0.001)$ \\
\hline \multirow[t]{2}{*}{ Regular work } & & & & & $0.344^{* *}$ & $0.888^{* * *}$ & $0.297^{* *}$ & $0.696^{* * *}$ & $0.300 * *$ & $0.707^{* * *}$ & $0.299^{* *}$ & $0.698^{* * *}$ \\
\hline & & & & & $(0.142)$ & $(0.009)$ & $(0.147)$ & $(0.010)$ & $(0.145)$ & $(0.010)$ & $(0.147)$ & $(0.010)$ \\
\hline \multirow[t]{2}{*}{ Leave Lombardy } & & & & & & & 0.036 & 0.014 & & & & \\
\hline & & & & & & & $(0.142)$ & $(0.0202)$ & & & & \\
\hline \multirow{2}{*}{$\begin{array}{l}\text { Return to home } \\
\text { country }\end{array}$} & & & & & & & & & 0.114 & $0.217^{* * *}$ & 0.111 & $0.199 * * *$ \\
\hline & & & & & & & & & $(0.183)$ & $(0.040)$ & $(0.187)$ & $(0.043)$ \\
\hline \multirow[t]{2}{*}{ Move elsewhere } & & & & & & & & & & & -0.021 & $-0.180 * * *$ \\
\hline & & & & & & & & & & & $(0.173)$ & $(0.021)$ \\
\hline Constant & $-0,336$ & $-26.37 * * *$ & 0.111 & $-23.92 * * *$ & 0.285 & $-23.84 * * *$ & 0.476 & $-24.21 * * *$ & 0.464 & $-24.314 * * *$ & 0.470 & $2.945^{* * *}$ \\
\hline Observations & 1,275 & 1,173 & 1,250 & 1,148 & 1,250 & 1,148 & 1,156 & 1,065 & 1,156 & 1,065 & 1,156 & 1,065 \\
\hline
\end{tabular}

* Significant at the $10 \%$ level ${ }^{* *} 5 \%$ level ${ }^{* * *} 1 \%$ level.

The standard errors in parentheses are clustered by country of origin. 
Table 7: Probability of Remitting and Discrimination: Interaction Terms

\begin{tabular}{|c|c|c|c|}
\hline & \multicolumn{3}{|c|}{ Female sample } \\
\hline & Tobit & Tobit & Tobit \\
\hline \multirow[t]{2}{*}{ Workplace discr. } & $-2.155^{* * *}$ & $-1.345^{* * *}$ & $0.171 * *$ \\
\hline & $(0.068)$ & $(0.070)$ & $(0.085)$ \\
\hline \multirow[t]{2}{*}{ Discr.*Income } & $0.291 * * *$ & & \\
\hline & $(0.010)$ & & \\
\hline \multirow[t]{2}{*}{ Discr.*Education } & & $0.365^{* * *}$ & \\
\hline & & $(0.013)$ & \\
\hline \multirow[t]{2}{*}{ Discr. ${ }^{*}$ Duration of stay } & & & $-0.054 * * *$ \\
\hline & & & $(0.006)$ \\
\hline \multirow[t]{2}{*}{ Income } & $0.577 * * *$ & $0.607 * * *$ & $0.593 * * *$ \\
\hline & $(0.002)$ & $(0.002)$ & $(0.001)$ \\
\hline \multirow[t]{2}{*}{ Education } & $-0.198 * * *$ & $-0.272 * * *$ & $-0.207 * * *$ \\
\hline & $(0.002)$ & $(0.002)$ & $(0.002)$ \\
\hline \multirow[t]{2}{*}{ Duration of stay } & $-0.097 * * *$ & $-0.094 * * *$ & $-0.089 * * *$ \\
\hline & $(0.001)$ & $(0.001)$ & $(0.000)$ \\
\hline \multirow[t]{2}{*}{ Constant } & $-24.09 * * *$ & $-23.85 * * *$ & $-24.14 * * *$ \\
\hline & $(0.012)$ & $(0.012)$ & $(0.012)$ \\
\hline Observations & 1,065 & 1,065 & 1,065 \\
\hline
\end{tabular}

Significant at the $10 \%$ level ** $5 \%$ level *** $1 \%$ level.

The standard errors in parentheses are clustered by country of origin. 


\section{Conclusion}

Despite discrimination against immigrants and their offspring remaining a key issue affecting the labour market in most OECD countries (OECD, 2013), little research has been devoted to the effect of immigrants' economic discrimination on remittances.

Using survey data from the Foundation for Initiatives and Studies on MultiEthnicity (ISMU) which monitors the immigration experience to the Lombardy region, the most preferred immigration destination in Italy, this paper originally aims to quantify the relationship between perceived economic discrimination and amount remitted (intensive margin), conditional on remitting at all (extensive margin).

Two possible channels can be at work and have been therefore tested in this research: a decrease in individual income as well as an increasing return intention.

Empirical results show that, beside traditional individual characteristics, a more discriminating destination environment leads to lower amount of remittances but only for women. The effect mainly goes through female immigrants' labour market conditions and only slightly through the willingness to leave Lombardy. Moreover, controlling for non linearities, the empirical results have also shown that the remittances-reducing effect of workplace discrimination applies particularly to female migrants who are less educated, have a low income and are long-settled.

The results are noteworthy since, as history has shown, the systematic alienation of particular social groups can come with costly economic consequences. In this paper we provide evidence that economic inequality experienced by immigrants in the destination country can have an indirect effect on economic conditions of the households left behind through a reduction of remittances sent back home. Indeed, given that migrant- sending countries are increasingly recognising the development potential of their diasporas (Licuanan et al., 2015), economic discrimination experienced by women at migration destinations can negatively affect it. 


\section{References}

Amuedo-Dorantes, C., Pozo, S. (2006). Remittances as insurance: evidence from Mexican immigrants. Journal of Population Economics 19 (2), 227-254.

Baio, G., Blangiardo, G. and M. Blangiardo (2011). Centre Sampling Technique in For- eign Migration Surveys: A Methodological Note. Journal of Official Statistics, Vol. 27(3), 451-465.

Batista, C. and J. Umblijs (2015). Do Migrants Send Remittances as a Way of Self- Insurance? Evidence from a Representative Immigrant Survey. Oxford Economic Papers, forthcoming.

Bettin, G. and E. Cela (2014). The evolution of migration flows in Europe and Italy. Economia Marche - Journal of Applied Economics, 33(1), 37-63.

Bettin, G., Lucchetti, R., and A. Zazzaro (2012). Endogeneity and sample selection in a model for remittances. Journal of Development Economics 99 (2), 370-384.

Bollard, A., D. McKenzie, M. Morten and H. Rapoport (2011). Remittances and the Brain Drain Revisited: The Microdata Show that More Educated Migrants Remit More. World Bank Economic Review, 25 (1), 132-156.

Carling, J. (2008). The Determinants of Migrant Remittances. Oxford Review of Economic Policy. 24(3), 582-599.

Carling, J. and K. Hoelscher (2013). The Capacity and Desire to Remit: Comparing Local and Transnational Influences. Journal of Ethnic and Migration Studies, 39(6), 939-958.

Cortes, P. (2015). The Feminization of International Migration and its effects on the Children Left behind: Evidence from the Philippines. World Development. 65, 62-78.

Daldy, B., J. Poot and M. Roskruge (2013). Perception of Workplace Discrimination Among Immigrants and Native Born New Zealanders. Australian Journal of Labour Economics. 16(1), 137-154.

Dancygier, R.M. and D.D. Laitin (2014). Immigration into Europe: Economic Discrimination, Violence, and Public Policy. Annual Review of Political Science, 17, 43-64.

Di Saint Pierre, F., Martinovic, B. and T. de Vroome (2015). Return wishes of refugees in the Netherlands: The role of integration, host national identification and perceived discrimination. Journal of Ethnic and Migration Studies, in press. 
Docquier, F. and H. Rapoport (2006). The Economics of migrants' remittances. In J. Mercier-Ythier et S.C. Kolm (eds), Handbook on the economics of giving, altruism and reciprocity, Handbook series edited by Kenneth Arrow and Michael Intriligator, Elsevier- North Holland, (2006), chapter 17.

Dustmann, C. and J.S. Gorlach (2015). The Economics of Temporary Migration. Journal of Economic Literature, forthcoming.

Dustmann, C. and J. Mestres (2010). Remittances and Temporary Migration, Journal of Development Economics, 92(1), 62-70.

Falco, C. and Gobel, K. (2015). Does the desire to remit foster integration? Evidence from migrants in Spain, Economics Letters 137 (2015) 131134.

Gorodzeisky A. and M. Semyonoy (2006). Labour Migration, Remittances and Household Income: A Comparison between Filipino and Filipina Overseas Workers. International Migration Review. 39(1), 45-68.

Jandl, M., D. Vogel, and K. Iglicka (2008). Report on methodological issues, Prepared for the research project CLANDESTINO.

Licuanan, V., Mahmoud, T. O. and Steinmayr, A. (2015). The Drivers of Diaspora Do- nations for Development: Evidence from the Philippines. World Development, 65, 94-109.

Lessem, R. (2013). Mexico-U.S. Immigration: Effects of Wages and Border Enforcement. Working paper.

Le Goff, M. and S. Salomone. 2015. 'Remittances and the changing composition of migration'. The World Economy, Volume 39, Issue 4, 513-529.

Lowell, B.L., Teachman, J. and Z. Jing (1995). Unintended Consequences of Immigration Reform: Discrimination and Hispanic Employment. Demography, 32(4) 617-628.

Lowell, L. and E.A. Marcelli (2005). Transnational Twist: Pecuniary Remittances and the Socioeconomic Integration of Authorized and Unauthorized Mexican Immigrants in Los Angeles County. International Migration Review, 39(1), 69-102.

Ng, I.F.S., Lee, S.Y., Wong, W.K.F., and K.L. Chou (2015). Effects of Perceived Dis- crimination on the Quality of Life Among New Mainland Chinese Immigrants to Hong Kong: A Longitudinal Study. Social Indicators Research, 120,817834 . 
OECD (2014). International Migration Outlook 2014, OECD Publishing. Paris.

OECD (2013). Discrimination against immigrants' measurement, incidence and policy instruments, in OECD, International Migration Outlook 2013, OECD Publishing, Paris.

Ozden, Ç. (2006). Educated Migrants: Is There Brain Waste? in International Migration, Remittances, and the Brain Drain, edited by Ç. Ozden and M. Schi. Washington D.C.: World Bank.

Siegel, M. (2007). Immigrant Integration and Remittance Channel Choice. Working Pa- per MGSoG/2007/WP009.

Stark, O. (1991). The Migration of Labour. Cambridge, MA: Basil Blackwell.

UNFPA (2006). Female Migrants: bridging the gaps throughout the life cycle. New York.

Vogel, D. and V. Kovacheva (2008). Classification report: Quality assessment of estimates on stocks of irregular migrants, Hamburg Institute of International Economics, Database on Irregular Migration, Working Paper No. 1/2008.

Yip, T., Gee, G.C. and D.T. Takeuchi (2008). Racial Discrimination and Psychological Distress: The Impact of Ethnic Identity and Age Among Immigrant and United States Born Asian Adults. Development Psychology, 44(3), 787-800.

Wolff, F. C. (2013). Do return intentions of French migrants affect their remittance behaviour? Mimeo

\section{A List of origin countries}

The original list of origin countries includes: Afghanistan, Albania, Algeria, Angola, Argentina, Armenia, Azerbaijan, Bahrain, Bangladesh, Belarus, Belize, Benin, Bhutan, Bolivia, Bosnia and Herzegovina, Brazil, Bulgaria, Burkina Faso, Burundi, Cambodia, Cameroon, Cape Verde, Central African Republic, Chad, Chile, China, Colombia, Comoros, Congo, Costa Rica, Croatia, Cuba, Czech Republic, Democratic Republic of the Congo, Dominica, Dominican Republic, Ecuador, Egypt, El Salvador, Eritrea, Estonia, Ethiopia, Gambia, Georgia, Ghana, Guinea, Guinea Bissau, Haiti, Honduras, Hungary, India, Indonesia, Iran, Iraq, Ivory Coast, Jamaica, Jordan, Kazakhstan, Kenya, Kyrgyzstan, Kosovo, Lebanon, Latvia, Liberia, Libya, Lithuania, Macedonia, Madagascar, Malaysia, Maldives, Mali, Mauritania, Mauritius, Mexico, Moldavia, Mongolia, Montenegro, Morocco, Mozambique, Myanmar, 
Namibia, Nepal, Nicaragua, Niger, Nigeria, North Korea, Pakistan, Palestinian Territory, Panama, Paraguay, Peru, Philippines, Poland, Romania, Russia, Rwanda, Saint Vincent and the Grenadines, Senegal, Serbia, Seychelles, Sierra Leone, Slovakia, Slovenia, Somalia, South Korea, South Africa, Sri Lanka, Sudan, Syria, Taiwan, Tanzania, Thailand, Togo, Tunisia, Turkey, Ukraine, Uganda, United Arab Emirates, Uruguay, Uzbekistan, Venezuela, Vietnam, Zambia 